\title{
Web@30: A Vote for Digital Ethics
}

\author{
K. POULOSE JACOB \\ Cochin University of Science and Technology Cochin 682022, Kerala, India.

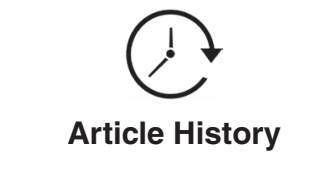 \\ Published on 23 April 2019
}

\begin{abstract}
Pearls are enduring and last under pressure, so is the web. But in its Pearl-jubilee, not all are shining in the web as pearls do. Is World Wide Web the web we would love to have in every respect? Tim Berners-Lee, whose initial proposal at CERN, Geneva in March 1989 opened the way to a technological revolution which influenced human kind more than anything, appeared a bit dismayed in his words of reminiscence during the Web@30 conference at CERN to commemorate the 30 years of Web. His dismay is not without reason. With tremendous impact, WWW has made the world smaller, more comfortable to live in in terms of convenience in transacting business of any kind in its broadest sense, has facilitated prefixing the ever so attractive word digital to many an entity, like digital world, digital economy, digital art, digital entertainment et cetera, with far reaching applications. Digital citizenry potentially unfolds when any child, teen, or adult signs up for an email address, posts pictures online, uses e-commerce to buy merchandise online, or participates in any electronic function that is B2C or B2B; then a netizen is born. Netizen population as on March 2019 has reached $56 \%$ of world population
\end{abstract}

With its genesis as a forum for creative minds to collaborate, it quite miserably acquired other attires like that of an agent who would scoop up personal data to be used for commercial purposes, of individuals misusing it to malign others and settle scores, of political parties using the web as a medium to scuttle elections, and so on. It is felt important to strike a balance between freedom on the web and responsibility towards its intended usage. Digital ethics is a phrase to be coined, in this scenario and needing to be propagated among the stake holders for voluntary adherence.

The beauty of the web lies in its neutrality and unfettered service to its myriad recipients. The moment an external control authority needs to step in for whatever reason, the true spirit of its mission recedes. There has been attempt to usurp the role of gate-keeping with commercial interests, which appeared as a threat to net neutrality; this met with stiff resistance from the netizen community. Access to all sites, content and

CONTACT K. Poulose Jacob kpj@ cusat.ac.in 9 Cochin University of Science \& Technology Cochin 682022, Kerala, India. (c) (i)

(C) 2018 The Author(s). Published by Oriental Scientific Publishing Company

This is an Open Access article licensed under a Creative Commons license: Attribution 4.0 International (CC-BY).

Doi: http://dx.doi.org/10.13005/ojcst12.01.01 
applications is to be provided at the same speed, under the same conditions without blocking or adopting any priced classification of content.

A fellow Netizen needs to be looked at just as we see our compatriots in the civil society, affording all shades of decency and courtesy. Social networking service companies, providing means to connect with friends, family and other people one knows, share photos and videos, send messages and get updates, have made social life a shade different. These forums find extensive usage to convey, if not propagate viewpoints and ideas. The sad part is that at times the ideas and thoughts turn out to be malicious and fraught with ill intentions, which tantamount to cybercrimes.

Ones actions and revelations on the web shall be such that they command respect if not admiration in the connected world, just as one would wish to conduct him/herself in the society.

The pictorial maxim of the three wise monkeys embodying the proverbial principle, "see no evil, hear no evil, speak no evil", shall be the doctrine for digital ethics as well.

Can the web be provided with intelligence to identify and isolate "evil"? Can "evil" in the web scenario, be defined as certain typical word-streams, dependent on the broad area of discourse? A discourse is composed of semiotic sequences (relations among signs that communicate meaning) between and among objects, subjects, and statements. Investigations in such directions, perhaps may lead to fortifying the web further.

\section{Reference}

1. WwW.internetworldstats.com.

2. ACM TECH NEWS, March 13, 2019

3. Glimpses of unfamiliar Japan volume 2, page 127

4. The Archaeology of Knowledge. Trans. A. M. Sheridan Smith. London and New York: Routledge, 2002.

5. Online Etymology Dictionary, (C) 2010 Douglas Harper 